\title{
Measuring self-reported change in alcohol and cannabis consumption during the second wave of the COVID-19 pandemic in Canada
}

\section{Mélanie Varin, MSc; Kate Hill MacEachern, PhD; Nousin Hussain, MPH; Melissa M. Baker, PhD}

(Published online 27 September 2021)

Tweet this article

\begin{abstract}
This study presents nationally representative estimates of self-reported changes in alcohol and cannabis consumption since the onset of COVID-19 in Canada. We used data from the Survey on COVID-19 and Mental Health (collected from September to December 2020) to calculate the prevalence of self-reported change in alcohol and cannabis consumption. We found that $15.7 \%$ of respondents self-reported an increase in alcohol consumption and $5.4 \%$ in cannabis consumption since the start of the pandemic. Sociodemographic disparities were also observed, indicating that increased alcohol and cannabis consumption may be more prevalent among certain populations.
\end{abstract}

\section{Introduction}

On 25 January 2020, Canada confirmed its first case of the novel coronavirus (COVID19) and by early March 2020, community transmission was apparent. Since then, rigorous public health guidelines and measures, such as hand hygiene, mandating masks, school closures and physical distancing protocols, have been implemented in Canada. These public health measures have had a critical role in mitigating the spread of COVID-19 to protect the health of Canadians. However, there is increasing evidence that the pandemic and these ensuing strict public health measures have had a negative impact on the mental health and well-being of Canadians..$^{1-3}$

Data from the first wave of the COVID-19 pandemic in Canada have shown increased prevalence of stress, anxiety and depression, ${ }^{1-5}$ which are known risk factors for the onset and sustained misuse of substances, such as alcohol ${ }^{6-8}$ and cannabis. ${ }^{9}$ A study initiated by Mental Health Research Canada found that one-third of participants aged 18 years and above who reported having a previous diagnosis of anxiety ( $\mathrm{n}=307)$ or depression $(\mathrm{n}=325)$ also reported an increase in alcohol and cannabis use during the pandemic. ${ }^{4}$

Furthermore, data collected between 29 March and 3 April 2020 from a national survey of 4383 participants aged 25 years and older indicate that $14 \%$ of respondents reported increased alcohol consumption and 5.5\% reported increased cannabis consumption during the first wave of the pandemic. ${ }^{10}$ Findings from early in the second wave (from 14 to 21 September 2020) among Canadian adults are consistent, with $40 \%$ of 3027 participants from one study indicating their mental health had deteriorated since the onset of the pandemic. ${ }^{11}$ Moreover, during the same period, increased alcohol and cannabis use was reported for $30 \%$ and $20 \%$, respectively, of individuals with a preexisting mental health condition. ${ }^{11}$ These findings highlight the intricate relationship between mental health and substance use.

These results are a significant and pressing public health concern, suggesting a

\section{Highlights}

- From 11 September to 4 December $2020,15.7 \%$ and $5.4 \%$ of individuals self-reported an increase in alcohol and cannabis consumption, respectively, compared to before the pandemic.

- Individuals who reported that their mental health was worse now, compared to before the pandemic, had the highest prevalence of selfreported increase in alcohol and cannabis consumption.

- Understanding the social determinants of health is critical to the development of harm reduction and mitigation strategies.

widespread impact of the pandemic on behavioural health. ${ }^{12}$ As the country works towards a national recovery plan in response to the repercussions and longterm consequences of the COVID-19 pandemic, more national data on population health behaviours, such as substance use, are needed to help inform public health guidance. Such guidance includes creating public health messages focussed on mitigating harms associated with alcohol and cannabis use. To date, there has been limited national information on alcohol and cannabis consumption during the second wave of the pandemic in Canada. The objective of this At-a-glance article is to (1) estimate the self-reported change in alcohol and cannabis use during the second wave of the COVID-19 pandemic, and (2) disaggregate self-reported increase in

\section{Author reference:}


alcohol and cannabis use by sociodemographic characteristics and self-reported change in mental health.

\section{Methods}

\section{Data collection and sampling}

We used data from the Survey on COVID19 and Mental Health (SCMH), which is a cross-sectional survey developed and funded by Statistics Canada and the Public Health Agency of Canada (PHAC). This survey was administered to 30000 dwellings from 11 September to 4 December 2020 with the purpose of capturing information related to mental health and wellbeing. A simple random sample was selected for each province and the territorial capitals. Of the 14689 people who responded to the survey, $84 \%$ agreed to share their data with PHAC, resulting in a sample size of 12344 for this analysis. Individuals living on reserves or other Indigenous settlements, full-time members of the Canadian Armed Forces and individuals in institutions were excluded from the survey coverage. Further detail about the SCMH design and sampling framework can be found on Statistics Canada's website. ${ }^{13}$

\section{Self-reported change in alcohol and cannabis consumption}

Respondents were asked, "How has your alcohol consumption changed since before the COVID-19 pandemic?" and "How has your cannabis consumption changed since before the COVID-19 pandemic?" Response options were: "Increased", "Decreased" and "No change". If respondents overlooked or refused to answer the questions, the data were considered as missing and the respondents were excluded from the analysis $(\mathrm{n}=43)$.

\section{Data analysis}

We estimated the weighted prevalence (with $95 \%$ confidence interval [CI]) of selfreported (1) increased change, (2) decreased change or (3) no change in alcohol and cannabis consumption among individuals aged 18 years and older. Estimates of selfreported increase were disaggregated by gender; age group; income change since COVID-19 (increased, decreased, no change); self-reported household income quintile; number of people in household; being a parent or legal guardian of a child or children under the age of 18 years; education level (less than high school, high school
TABLE 1

Characteristics of respondents in study on changes in alcohol and cannabis consumption since the beginning of the COVID-19 pandemic, Canada, September to December 2020

\begin{tabular}{|c|c|}
\hline Variable & $\begin{array}{c}\text { Proportion, \% } \\
\quad(95 \% \mathrm{CI})\end{array}$ \\
\hline \multicolumn{2}{|l|}{ Gender } \\
\hline Male & $49.1(48.9-49.3)$ \\
\hline Female & $50.7(50.6-50.7)$ \\
\hline \multicolumn{2}{|l|}{ Age group } \\
\hline 18-24 years & $9.5(8.6-10.4)$ \\
\hline $25-34$ years & $18.7(17.8-19.6)$ \\
\hline $35-44$ years & $16.8(16.8-16.8)$ \\
\hline $45-54$ years & $15.6(15.6-15.6)$ \\
\hline $55-64$ years & $17.2(17.2-17.2)$ \\
\hline $65+$ years & $22.2(22.2-22.2)$ \\
\hline \multicolumn{2}{|l|}{ Income change since COVID-19 } \\
\hline Increased & $6.0(5.3-6.7)$ \\
\hline Decreased & $37.5(36.3-38.8)$ \\
\hline No change & $56.5(55.2-57.7)$ \\
\hline \multicolumn{2}{|c|}{ Self-reported total household income quintile } \\
\hline Q1 & $21.1(20.0-22.2)$ \\
\hline Q2 & $20.2(19.1-21.3)$ \\
\hline Q3 & $22.4(21.2-23.6)$ \\
\hline Q4 & $18.3(17.2-19.4)$ \\
\hline Q5 & $18.0(16.9-19.1)$ \\
\hline \multicolumn{2}{|l|}{ Province/territorial capital } \\
\hline British Columbia & $13.4(13.4-13.4)$ \\
\hline Alberta & $11.4(11.4-11.4)$ \\
\hline Saskatchewan & $2.8(2.8-2.8)$ \\
\hline Manitoba & $3.3(3.3-3.3)$ \\
\hline Ontario & $39.5(39.5-39.5)$ \\
\hline Quebec & $22.9(22.9-22.9)$ \\
\hline New Brunswick & $2.0(2.0-2.0)$ \\
\hline Nova Scotia & $2.6(2.6-2.6)$ \\
\hline Prince Edward Island & $0.4(0.4-0.4)$ \\
\hline Newfoundland and Labrador & $1.4(1.4-1.4)$ \\
\hline Whitehorse, Yukon & $0.1(0.1-0.1)$ \\
\hline Yellowknife, Northwest Territories & $0.1(0.1-0.1)$ \\
\hline Iqaluit, Nunavut & $0.02(0.02-0.02)$ \\
\hline \multicolumn{2}{|l|}{ Place of residence } \\
\hline Urban & $82.3(81.5-83.1)$ \\
\hline Rural & $17.7(16.9-18.5)$ \\
\hline \multicolumn{2}{|l|}{ Number of people in household } \\
\hline 1 & $14.5(14.1-14.9)$ \\
\hline 2 & $35.5(34.8-36.2)$ \\
\hline 3 & $17.5(16.5-18.5)$ \\
\hline 4 & $18.6(17.4-19.7)$ \\
\hline 5 and more & $13.9(12.7-15.1)$ \\
\hline
\end{tabular}

Continued on the following page 
graduate, postsecondary graduate); selfidentification as part of a racialized group (yes/no); immigrant status; province/territorial capital; place of residence (urban/ rural); and self-reported changes in mental health compared to before the pandemic.

Survey sampling weights were provided by Statistics Canada to generate nationally representative estimates. Variance was estimated using the bootstrap method, and SAS Enterprise Guide version 7.1 (SAS Institute Inc., Cary, NC, USA) was used for statistical analyses. Chi-square tests were conducted to examine significant associations between sociodemographic variables, self-reported mental health and alcohol and cannabis consumption behaviours.

\section{Results}

Based on nationally representative data, $15.7 \%$ of individuals self-reported an increase in alcohol consumption, 9.9\% self-reported a decrease and $74.3 \%$ selfreported no change. For cannabis, 5.4\% self-reported an increase in consumption, $1.8 \%$ self-reported a decrease, $19.5 \%$ selfreported no change and $73.3 \%$ self-reported never using cannabis. The prevalence estimates for increased alcohol or cannabis consumption varied after disaggregation. Statistically significant differences are highlighted in the Results section of this article, and all estimates can be found in Tables 1 and 2 .

\section{Alcohol consumption}

The prevalence of self-reported increased alcohol consumption was higher among individuals aged 35 to 44 years (21.9\%) and 45 to 54 years $(21.0 \%)$, those with a postsecondary education (18.4\%), and individuals who reported a change in their household income since COVID-19 (18.5\% increased income, 19.1\% decreased income). The prevalence of self-reported increased alcohol consumption augmented by income quintile (ranging from $7.5 \%$ to $27.2 \%$ ). Yellowknife, Northwest Territories, (22.5\%) had the highest prevalence of self-reported increase in alcohol consumption, while Prince Edward Island (11.0\%) had the lowest prevalence. The percentage of selfreported increase in alcohol consumption was higher for individuals living in an urban area (16.2\%), living in a household with four people $(20.8 \%)$, parents or legal guardians of children under the age of 18 years $(22.6 \%)$, born in Canada ("nonimmigrants”) (18.2\%) and people who
TABLE 1 (continued)

Characteristics of respondents in study on changes in alcohol and cannabis consumption since the beginning of the COVID-19 pandemic, Canada, September to December 2020

\begin{tabular}{|c|c|}
\hline Variable & $\begin{array}{c}\text { Proportion, \% } \\
\quad(95 \% \mathrm{Cl})\end{array}$ \\
\hline \multicolumn{2}{|c|}{ Parent/legal guardian of a child or children under 18 years } \\
\hline Yes & $27.6(26.6-28.5)$ \\
\hline No & $72.4(71.5-73.4)$ \\
\hline \multicolumn{2}{|l|}{ Education level } \\
\hline Less than high school & $7.6(6.9-8.3)$ \\
\hline High school graduate & $23.6(22.4-24.8)$ \\
\hline Postsecondary graduate & $68.8(67.5-70.0)$ \\
\hline \multicolumn{2}{|c|}{ People who self-identify as part of a racialized group } \\
\hline Yes & $24.3(23.1-25.4)$ \\
\hline No & $75.7(74.6-76.9)$ \\
\hline \multicolumn{2}{|l|}{ Immigrant } \\
\hline Yes & $25.6(24.4-26.8)$ \\
\hline No & $73.0(71.8-74.1)$ \\
\hline Non-permanent resident & $1.4^{\mathrm{E}}(1.1-1.8)$ \\
\hline \multicolumn{2}{|c|}{ Self-rated mental health compared to before the COVID-19 pandemic } \\
\hline Much better now/somewhat better now & $7.6(6.8-8.3)$ \\
\hline About the same & $59.0(57.6-60.3)$ \\
\hline Much worse now/somewhat worse now & $33.5(32.2-34.8)$ \\
\hline \multicolumn{2}{|c|}{ Self-reported change in alcohol consumption } \\
\hline Increased & $15.7(14.7-16.7)$ \\
\hline Decreased & $9.9(9.1-10.8)$ \\
\hline No change & $74.3(73.2-75.5)$ \\
\hline \multicolumn{2}{|c|}{ Self-reported change in cannabis consumption } \\
\hline Increased & $5.4(4.8-6.1)$ \\
\hline Decreased & $1.8(1.4-2.1)$ \\
\hline No change & $19.5(18.4-20.5)$ \\
\hline Never used cannabis & $73.3(72.1-74.5)$ \\
\hline
\end{tabular}

Data source: 2020 Survey on COVID-19 and Mental Health.

Abbreviations: $\mathrm{Cl}$, confidence interval; $\mathrm{Q}$, quintile.

${ }^{\mathrm{E}}$ As per the Survey on COVID-19 and Mental Health release guidelines, prevalence estimates should be interpreted with caution, as the unweighted total sample size is between 75 and 150 . Please look at the confidence intervals when interpreting these estimates.

did not identify as being part of a racialized group $(17.8 \%)$. Lastly, the rate of increased alcohol consumption was highest among people who reported that their mental health was much worse or somewhat worse now compared to before the COVID-19 pandemic (27.0\%).

\section{Cannabis consumption}

The prevalence of self-reported increased cannabis consumption was higher for males (5.8\%), non-immigrants $(6.3 \%)$, people who reported that their income had decreased $(7.9 \%)$ since the beginning of COVID-19 pandemic and individuals who self-reported that their mental health was much worse now/somewhat worse now $(10.0 \%)$. Self-reported increased cannabis consumption decreased by age (ranging from $12.1 \%$ to $1.0 \%$ ), was highest in Nova Scotia (7.8\%) and lowest in Saskatchewan (3.0\%).

\section{Discussion}

Overall, we found that $15.7 \%$ of individuals living in Canada self-reported an increase in their alcohol consumption and $5.4 \%$ self-reported an increase in their cannabis consumption during the second wave of the COVID-19 pandemic. Selfreported increase in alcohol and cannabis use were disaggregated by sociodemographic 
TABLE 2

Percentage of self-reported increase in alcohol and cannabis consumption since COVID-19, disaggregated by sociodemographic characteristics, adults aged 18 years and older, Canada, September to December 2020

\begin{tabular}{|c|c|c|c|c|}
\hline Variable & $\begin{array}{l}\% \text { of self-reported increase in } \\
\text { alcohol consumption } \\
(95 \% \mathrm{Cl})\end{array}$ & $p$-value & $\begin{array}{l}\% \text { of self-reported increase in } \\
\text { cannabis consumption } \\
(95 \% \mathrm{Cl})\end{array}$ & $p$-value \\
\hline \multicolumn{5}{|l|}{ Gender } \\
\hline Male & $15.2(13.8-16.6)$ & \multirow{2}{*}{0.5902} & $5.8(4.8-6.8)$ & \multirow{2}{*}{$<0.001$} \\
\hline Female & $16.2(14.9-17.5)$ & & $4.9(4.1-5.8)$ & \\
\hline \multicolumn{5}{|l|}{ Age group } \\
\hline $25-34$ years & $18.2(15.5-20.8)$ & \multirow{5}{*}{$<0.001$} & $9.8(7.7-12.0)$ & \multirow{5}{*}{$<0.001$} \\
\hline $35-44$ years & $21.9(19.6-24.3)$ & & $6.0(4.6-7.4)$ & \\
\hline $45-54$ years & $21.0(18.4-23.7)$ & & $4.4(3.2-5.7)$ & \\
\hline $55-64$ years & $13.8(11.9-15.7)$ & & $3.1(2.2-3.9)$ & \\
\hline $65+$ years & $7.3(6.0-8.6)$ & & $1.0(0.5-1.4)$ & \\
\hline No change & $13.3(12.2-14.3)$ & $<0.001$ & $3.8(3.1-4.5)$ & $<0.001$ \\
\hline \multicolumn{5}{|c|}{ Self-reported total household income quintile } \\
\hline Q1 & $7.5(6.0-9.0)$ & \multirow{5}{*}{$<0.001$} & $4.2(3.0-5.4)$ & \multirow{5}{*}{0.1351} \\
\hline Q2 & $12.7(10.7-14.7)$ & & $5.0(3.7-6.4)$ & \\
\hline Q3 & $15.9(13.8-18.1)$ & & $6.5(4.7-8.2)$ & \\
\hline Q4 & $21.1(18.5-23.8)$ & & $6.7(5.1-8.2)$ & \\
\hline Q5 & $27.2(24.2-30.2)$ & & $5.6(3.7-7.4)$ & \\
\hline \multicolumn{5}{|l|}{ Province/territorial capital } \\
\hline British Columbia & $19.2(16.6-21.8)$ & \multirow{7}{*}{0.0013} & $5.0(3.4-6.6)$ & \multirow{7}{*}{$<0.001$} \\
\hline Nova Scotia & $16.5(13.4-19.5)$ & & $7.8(5.6-9.9)$ & \\
\hline Prince Edward Island & $11.0(8.4-13.5)$ & & $5.5(3.5-7.4)$ & \\
\hline Newfoundland and Labrador & $14.0(11.1-16.9)$ & & $4.1(2.5-5.8)$ & \\
\hline Whitehorse, Yukon & $17.7(13.8-21.6)$ & & $5.3(2.9-7.6)$ & \\
\hline Yellowknife, Northwest Territories & $22.5(17.1-27.9)$ & & $5.9(3.1-8.6)$ & \\
\hline Iqaluit, Nunavut & $18.0(12.1-23.9)$ & & $6.4(2.5-10.3)$ & \\
\hline \multicolumn{5}{|l|}{ Place of residence } \\
\hline Urban & $16.2(15.1-17.3)$ & \multirow{2}{*}{0.0105} & $5.6(4.8-6.3)$ & \multirow{2}{*}{0.3146} \\
\hline Rural & $13.1(11.2-15.1)$ & & $4.7(3.3-6.1)$ & \\
\hline \multicolumn{5}{|l|}{ Number of people in household } \\
\hline 1 & $11.9(10.4-13.4)$ & \multirow{5}{*}{$<0.001$} & $5.3(4.2-6.3)$ & \multirow{5}{*}{0.3663} \\
\hline 2 & $13.5(12.2-14.8)$ & & $4.9(4.1-5.8)$ & \\
\hline 3 & $17.1(14.6-19.6)$ & & $5.1(3.6-6.6)$ & \\
\hline 4 & $20.8(18.0-23.5)$ & & $6.9(4.8-9.0)$ & \\
\hline 5 and more & $17.0(13.6-20.4)$ & & $5.5(3.2-7.8)$ & \\
\hline
\end{tabular}


TABLE 2 (continued)

Percentage of self-reported increase in alcohol and cannabis consumption since COVID-19, disaggregated by sociodemographic characteristics, adults aged 18 years and older, Canada, September to December 2020

\begin{tabular}{|c|c|c|c|c|}
\hline Variable & $\begin{array}{l}\% \text { of self-reported increase in } \\
\text { alcohol consumption } \\
(95 \% \mathrm{Cl})\end{array}$ & $p$-value & $\begin{array}{l}\text { \% of self-reported increase in } \\
\text { cannabis consumption } \\
(95 \% \mathrm{Cl})\end{array}$ & $p$-value \\
\hline \multicolumn{5}{|c|}{ Parent/legal guardian of a child or children under $\mathbf{1 8}$ years } \\
\hline Yes & $22.6(20.6-24.5)$ & \multirow{2}{*}{$<0.001$} & $4.8(3.8-5.7)$ & \multirow{2}{*}{0.1749} \\
\hline No & $13.1(12.0-14.2)$ & & $5.7(4.8-6.5)$ & \\
\hline \multicolumn{5}{|l|}{ Education level } \\
\hline High school graduate & $11.5(9.5-13.5)$ & \multirow[t]{2}{*}{$<0.001$} & $5.3(3.9-6.7)$ & \multirow[t]{2}{*}{0.3849} \\
\hline Postsecondary graduate & $18.4(17.2-19.6)$ & & $5.7(4.9-6.5)$ & \\
\hline \multicolumn{5}{|c|}{ People who self-identify as part of a racialized group } \\
\hline Yes & $9.4(7.4-11.4)$ & \multirow{2}{*}{$<0.001$} & $5.1(3.5-6.8)$ & \multirow{2}{*}{0.6659} \\
\hline No & $17.8(16.7-18.9)$ & & $5.5(4.8-6.2)$ & \\
\hline \multicolumn{5}{|l|}{ Immigrant } \\
\hline Non-permanent resident & $14.5^{\mathrm{E}}(2.4-26.6)$ & $<0.001$ & $6.6^{\mathrm{E}}(0.2-12.9)$ & 0.0024 \\
\hline \multicolumn{5}{|c|}{ Self-rated mental health compared to before the COVID-19 pandemic } \\
\hline Much better now/somewhat better now & $13.6(10.3-16.9)$ & \multirow{3}{*}{$<0.001$} & $8.8(5.0-12.6)$ & \multirow{3}{*}{$<0.001$} \\
\hline About the same & $9.5(8.6-10.5)$ & & $2.4(1.8-3.0)$ & \\
\hline Much worse now/somewhat worse now & $27.0(24.9-29.1)$ & & $10.0(8.5-11.5)$ & \\
\hline
\end{tabular}

Data source: 2020 Survey on COVID-19 and Mental Health.

Abbreviations: $\mathrm{Cl}$, confidence interval; $\mathrm{Q}$, quintile.

${ }^{\mathrm{E}}$ As per the Survey on COVID-19 and Mental Health release guidelines, prevalence estimates should be interpreted with caution, as the unweighted total sample size is between 75 and 150 . Please look at the confidence intervals when interpreting these estimates.

characteristics and self-reported change in mental health, providing additional evidence of the wider impacts of the pandemic. Our result for cannabis was consistent with the increase reported early in the pandemic from 29 March to 3 April 2020 (first wave) in the Canadian Perspective Survey Series (CPSS) $(5.5 \%))^{10}$ Our estimate of increased alcohol consumption was slightly higher than what was found in series 1 of the CPSS $(14 \%) .{ }^{10}$

Once disaggregated, results differed by various sociodemographic variables, which indicates potential disparities for certain groups. The increase in consumption of alcohol and cannabis differed significantly by age group, province and change in household income since the beginning of the COVID-19 pandemic. Interestingly, the number of individuals who self-reported an increase in alcohol consumption increased with age, whereas increases in cannabis consumption appeared to decrease with age. Moreover, individuals who rated their mental health as much worse/somewhat worse compared to before the COVID-19 pandemic also had a higher proportion of increased alcohol (27\%) and cannabis consumption (10\%) compared to those who rated their mental health as about the same, or much better/ somewhat better now. This result is consistent with existing literature ${ }^{4,11}$ and highlights the complex relationship between mental health and alcohol and cannabis use.

We also observed substance-specific differences. Among those who self-reported an increase in alcohol consumption, significant differences were observed by household income quintile, place of residence (urban/rural), size and composition of household, and racialized groups. Interestingly, gender differences were not observed for alcohol use. Among those who self-reported an increase in cannabis consumption, proportionally more men reported an increase in cannabis consumption compared to women.

It is important to note that these estimates are representative of the entire survey population, including people who have never used alcohol or cannabis. These results would likely vary significantly if we restricted our sample to respondents who had used these substances before. As Canada is currently in the recovery stage, subsequent studies should continue monitoring alcohol and cannabis consumption for the entire population, which includes non-consumers, but also specifically for individuals who do consume these substances to inform public health prevention and harm reduction strategies. Future research evaluating certain policies that may have contributed to increased alcohol and cannabis use (for example, access to alcohol through home deliveries) is also warranted.

\section{Conclusion}

During the second wave of the COVID-19 pandemic in Canada, an estimated 15.7\% of Canadians self-reported an increase in their consumption of alcohol and $5.4 \%$ an increase in their consumption of cannabis. These nationally representative estimates varied by sociodemographic characteristics, which indicates the importance of understanding the social determinants of 
health. Future studies should focus on the association between the determinants and substance use during COVID-19 to help identify the at-risk populations that may benefit from increased awareness, mitigation efforts and resources pertaining to alcohol- and cannabis-related harms.

\section{Acknowledgements}

The authors would like to thank Lil Tonmyr (of the Public Health Agency of Canada) and Statistics Canada for their contribution to the design of the Survey on COVID-19 and Mental Health. We would like to thank Jeyasakthi Venugopal (Public Health Agency of Canada) for double-checking the analysis and results. We would also like to thank the staff at Statistics Canada and the Data Coordination and Access Program (DCAP) at the Public Health Agency of Canada for their assistance with data dissemination. We would like to thank every individual at Statistics Canada that participated in data collection. Lastly, we would like to thank all of the people who participated in this survey.

\section{Conflicts of interest}

The authors have no conflicts of interest to disclose.

\section{Authors' contributions and statement}

MV, KHM, NH and MB drafted this At-aglance article. MV did the statistical analyses. All co-authors interpreted the data, and revised the article.

The content and views expressed in this article are those of the authors and do not necessarily reflect those of the Government of Canada.

\section{References}

1. Mental Health Commission of Canada (MHCC), Nanos Research. Canadians report an increase in feeling stressed regularly or all the time now compared to one month before COVID-19. Ottawa (ON): MHCC; 2020. 69 p. Available from: https://www.mental healthcommission.ca/sites/default / files/2020-05/nanos_covid_ may_2020.pdf
2. Gadermann AC, Thomson KC, Richardson CG, et al. Examining the impacts of the COVID-19 pandemic on family mental health in Canada: findings from a national cross-sectional study. BMJ Open. 2021;11(1): e042871. https://doi.org/10.1136 /bmjopen-2020-042871

3. Hawke LD, Barbic SP, Voineskos A, et al. Impacts of COVID-19 on youth mental health, substance use, and well-being: a rapid survey of clinical and community samples. Can J Psychiatry. 2020;65(10):701-9. https:// doi.org/10.1177\%2F0706743720940562

4. Dozois DJ, Mental Health Research Canada. Anxiety and depression in Canada during the COVID-19 pandemic: a national survey. Can Psychol. 2021;62(1):136-42. https://doi.org/10 $.1037 /$ cap0000251

5. Schmitz N, Holley P, Meng X, Fish L, Jedwab J. COVID-19 and depressive symptoms: a community-based study in Quebec, Canada. Can J Psychiatry. 2020;65(10):733-5. https://doi.org/10 $.1177 / 0706743720943812$

6. Burns L, Teesson M. Alcohol use disorders comorbid with anxiety, depression and drug use disorders. Findings from the Australian National Survey of Mental Health and Well Being. Drug Alcohol Depend. 2002;68(3): 299-307. https://doi.org/10.1016/s0376 -8716(02)00220-x

7. Bolton J, Cox B, Clara I, Sareen J. Use of alcohol and drugs to self-medicate anxiety disorders in a nationally representative sample. J Nerv Ment Dis. 2006;194(11):818-25. https://doi .org/10.1097/01.nmd.0000244481 .63148 .98

8. Boschloo L, Vogelzangs N, Smit JH, et al. Comorbidity and risk indicators for alcohol use disorders among persons with anxiety and/or depressive disorders: findings from the Netherlands Study of Depression and Anxiety (NESDA). J Affect Disord. 2011;131(1-3):233-42. https://doi.org /10.1016/j.jad.2010.12.014
9. Schlossarek S, Kempkensteffen J, Reimer J, Verthein U. Psychosocial determinants of cannabis dependence: a systematic review of the literature. Eur Addict Res. 2016; 22(3):131-44. https://doi.org/10.1159 $/ 000441777$

10. Zajacova A, Jehn A, Stackhouse M, Denice P, Ramos H. Changes in health behaviours during early COVID-19 and socio-demographic disparities: a cross-sectional analysis. Can J Public Health. 2020;111(6):953-62. https:// doi.org/10.17269/s41997-020-00434-y

11. Canadian Mental Health Association (CMHA), University of British Columbia. Mental health impacts of COVID-19: wave 2. Toronto (ON): CMHA; 2020. 5 p. Available from: https://cmha.ca /wp-content/uploads/2020/12/CMHA -UBC-wave-2-Summary-of-Findings -FINAL-EN.pdf

12. Evans AC, Bufka LF. The critical need for a population health approach: addressing the nation's behavioral health during the COVID-19 pandemic and beyond. Prev Chronic Dis. 2020:17:200261. https://doi.org/10 $.5888 / \operatorname{pcd} 17.200261$

13. Statistics Canada. Survey on COVID19 and Mental Health (SMCH) [Internet]. Ottawa (ON): Statistics Canada; 2020. Available from: https://www23 .statcan.gc.ca/imdb/p2SV.pl?Function $=$ getSurvey $\& I d=1283036$ 